\title{
CREATION OF A REGIONAL COOPERATIVE NETWORK IN FRANCE FOR INTRATHECAL ANALGESIA
}

Boden $A^{1}$, Pouymayou J1, Combis $C^{2}$, Bourgouin-Ariba $M^{1}$, Mauries-Saffon $V^{1}$, Caunes-Hilary $N^{1}$

\section{INTRODUCTION AND CONTEXT}

Since its inception in the 1980s, the use of analgesic intrathecal (IT) infusion has constantly increased to treat patients with intractable pain. In cancer pain, this technique has a double aim :

- Reach a best pain control

- Improve quality of life

IT infusion allows this by reducing analgesic dose and side effects. However, only few patients with cancer pain benefit from IT therapy in France, because of the lack of reference centers and organized networks.

\section{IT ANALGESIA IN THE INSTITUT UNIVERSITAIRE DU CANCER DE TOULOUSE - ONCOPOLE}

The Institut Claudius Regaud (ICR) is a cancer treatment center in Toulouse, France. The ICR has been gathered with some oncology services of Toulouse University Hospital Center to create the Institut Universitaire du Cancer de Toulouse - Oncopole (IUCT-O) in 2014. As IT analgesia is used since 1998 in ICR (1998 for the first IT catheters, 2013 for implanted pumps), the IUCT-O has a referent role in French southwest area. At this time, we have implanted 106 pumps.

Actually, the patient path for an IT pump follows this pattern :

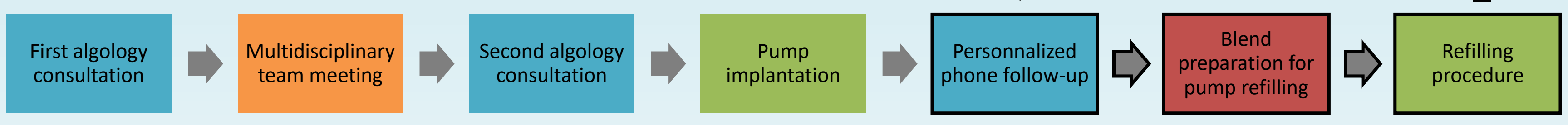

Nevertheless, because of long and regular journeys for refilling necessity, a lot of patients do not benefit from IT analgesia. So, we are trying to create a regional cooperative network in order to avoid patients long travel : IUCT-O should remain the referent center for implanting pumps, but refilling procedure would be done in local hospitals. This means that the three last steps (black box) should no longer be performed by IUCT-O for distant patients. Actually there are only two networks of this kind in France.

\section{BUILDING THE NETWORK}

The project is under discussion with french health authorities for about two years.

The first step has recently been reached : we have interviewed all the local players who are interested by this project, which represents 14 different hospitals, in a joint meeting. Several points have been raised :

- The number of pump implantions should certainly increase due to the creation of the network.

- IT infusion of morphine, ziconotide and local anesthesic is interesting for cancer pain. But, because of a narrow therapeutic window, ziconotide may not be used by some pharmacies. So, in some cases, the IUCT-O pharmacy (which is familiar with this treatment) may remain in charge of blend preparations, which will be sent in a second time to the different local hospitals.

- All the local teams should perform refilling and programming pump procedures, which should avoid patients long traveling.

- Eventually, for non transportable patients, refilling should ideally be performed at home.

After this meeting a formal commitment will be asked.

We are now working on the second step of the project : building an official formation for all our partnership teams. These teams are all multidisciplinary, including doctors, nurses and pharmacists. They also include several specialities like oncologist, palliative care practitioner and algologist. So the formation should be complete in order to give a high competence label, even if the local teams do not implant IT pumps.

French health authorities may be involved with a financial contribution for the formation and the prescription software.

\section{CONCLUSION}

